\title{
КИНЕТИКА СООКИСЛЕНИЯ 3,4-БЕНЗПИРЕНА, ФЕНОЛА И 5-МЕТИЛРЕЗОРЦИНА, АКТИВИРОВАННОГО УЛЬТРАФИОЛЕТОВЫМ ИЗЛУЧЕНИЕМ
}

Реакционная способность и физиологическая активность фенолов непосредственно связаны с особенностями их структуры $\left[{ }^{1-4}\right]$. Пассивные в аутоокислении оксибензо. и его простейшие гомологи способны усиливать воздействие на живой организм химических канцерогенов. Напротив, реакционноспособные резорцин и его производные лишены этих свойств и даже могут служить ингибиторами канцерогенеза [ $\left.{ }^{3,4}\right]$. В ряде исследований $\left[{ }^{5-7}\right]$ для фенолов и канцерогенных углеводородов установлено сходство результатов и, по-видимому, механизма деградации в биохимических процессах и при окислении, активированном ультрафиолетовым излучением.

С этих позиций представляет интерес попытка кннетической оценки совместного фотоокисления «классического» канцерогена, каким является 3,4-бензпирен, и фенолов разного строения. Результаты такой оценки приводятся в настоящем сообщении.

Данные о раздельной фотодеградации этих соединений опубликованы в литературе за последние годы. Так, первичный акт окислительного фотолиза фенолов в зависимости от $\mathrm{pH}$ среды сводится к образованию фенокси-радикалов или ионов $\left[{ }^{8}\right]$, которые в дальнейшем окисляются преимущественно до орто- и частично до пара-диоксипроиз. водных. Фотоокисление последних приводит к раскрытию ароматического кольца и образованию пировиноградной, муконовой и других кислот $\left[{ }^{9-12}\right]$, идентифицированных также в составе продуктов метаболического окисления фенолов $\left[{ }^{13-16}\right]$. Фотоокислительная деградация 3,4-бензпирена протекает лишь в присутствии сенсибилизатора, роль которого может играть возбужденный кислород $\left[{ }^{17-19}\right]$. Первичные продукты - соответствующие радикалы и карб-анионы или -катионы $\left.{ }^{20-24}\right]$ - подвержены дальнейшему превращению в 5,8- или 10-оксипроизводные бензпирена $[21,22,25,26]$. Совместное окисление 3,4-бензпирена и фенола описано лишь в $\left[{ }^{27}\right]$, где отмечается ингибирующее действие оксибензола на метаболическое гидроксилирование канцерогена.

\section{Объекты и методика исследования}

Эксперимент поставлен с растворами 3,4-бензпирена и двух фенолов - оксибензола и 5-мегилрезорцина, обладающих резко отличной реакционной способностью в аутоокислении и разнонаправленной физиологической активностью. В качестве полярного растворителя использован $96 \%$-ный этанол. Специальный цикл сравнительных кинетических опытов проведен с рагтвором извесгного сенсибилизатора реакций протонного выделения - калиевой солью эозина. Для исследования использованы химически чистыє реактивы (фирм Fluka AG, Buchs SG и Merck AG), оксибензол очищен дополнительно. 
Проба раствора помещается в герметичную колбу Әрленмейера с пришлифованной пробкой, которая снабжена прозрачной кварцевой крышкой-пластиной. Двух-трехминутная продувка реактора кислородом позволяет установить парциальное давление последнего на уровне 500 м. рт. ст. без окисления реакционной смеси. Условия постановки эксперимента обеспечивают ведение процесса в кинетической области. Далее последовательно включаются магнитная мешалка и лампа типа СВД-120-А, излучающая в диапазоне свыше 200 нм при максимуме испускания в области 365 нм. Интенсивность излучения проверяется актинометрически по методике из [28]. Состав реакционной смеси исследован по методике из $[29,30]$. Основной эксперимент был поставлен в двух циклах и при разных интенсивностях излучения (см. табл. 1). Каждый из них включает три группы опытов с деградацией того или иного компонента, который в данном случае считается основным, раздельно или совместно с одним из перечисленных выше соединений. Дополнительные опыты (четвертая группа в первом цикле) проведены при повышенной концентрации реагентов.

\section{Результаты исследования и их обсуждение}

Обработанные результаты кинетического исследования приведены в табл. 1. Для примера на рис. 1 дана группа типичных кинетических кривых, в данном случае характеризующих изменение во времени концентрации оксибензола как основного реагента (первая группа первого цикла). Все они, за исключением экспоненциальной кривой 2 в случае соокисле-

Таблица $f$

Макрокинетическая характеристика совместного фотоокисления 3,4-бензпирена, оксибензола и 5-метилрезорцина

Компоненты и их молярная концентрация Значение константы скорости, $10^{-5}$ сек-1, при интенсивности излучения, $10^{15} \kappa в а н т / м \Omega \cdot с е \kappa$

\begin{tabular}{l|l|l|l}
\hline Основной & Дополнительные & 8,3 & 32 \\
\hline
\end{tabular}

Оксибензол, $5 \cdot 10^{-4}$

3,4-Бензпирен, $\overline{2} \cdot 10^{-4}$
Эозин, $2,1 \cdot 10^{-5}$

5-Метилрезорцин, $6 \cdot 10^{-4}$

II группа опытов

5-Метилрезорцин, $6 \cdot 10^{-1}$

3,4 -Бензпирен, $\overline{2} \cdot 10^{-4}$

Оксибензол, $6 \cdot 10^{-4}$

Эозин, $2,1 \cdot 10^{-5}$

III группа опытов

3,4-Бензпирен, $2 \cdot 10^{-4}$

3,4-Бензпирен, $4 \cdot 10^{-4}$
Окснбензол, $5 \cdot \overline{1} 10^{-4}$

5-Метилрезорцин, $6 \cdot 10^{-4}$

Эозин, $2,1 \cdot 10^{-5}$

\section{IV группа опытов}

Оксибензол, 0,106

5-Метилрезорцин, 0,100
23,2 
ния с 3,4-бензпиреном (отвечающей уравнению первого порядка), свндетельствуют о нулевом порядке суммарной реакции.

Сопоставимость результатов исследования, относящегося к реакциям различного порядка и проведенного при разных концентрационных уровнях, достигается при использовании модифицированной константы скорости суммарного процесла, отражающего относительное изменение молярной концентрации $\Delta \mathrm{C} / \mathrm{C}_{0}$ в единицу времени и выражаемой в $c е \kappa^{-1}$.

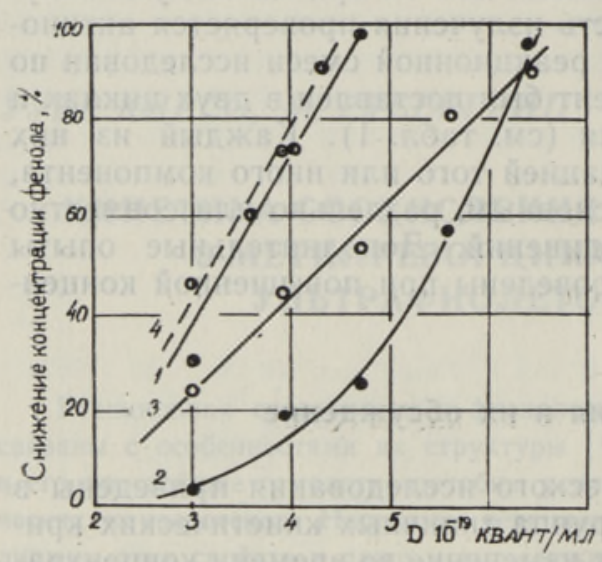

Рис. 1. Кинетика деградации оксибензола при интенсивности облучения $8,3 \cdot 10^{15} \kappa в а н т / \aleph л \cdot с е \kappa$.

1 - раздельное окисленне оксибензола, 2 - совместная деградация с 3,4-бензпире ном, 3 - соокисление с 5-метнлрезорцином, 4 - реакция в присутствии эозина.

Как видно из табл. 1, добавка любого второго компонента чаще всего сопровождается изменением скорости деградации основного реагента по сравнению с раздельным фотоокислением его. Так, деградация оксибензола ускоряется в присутствии эозина и замедляется при соокислении его с более активными акцепторами - 3,4-бензпиреном и 5 -метилрезорцином. Окисление 5-метилрезорцина сенсибилизируется не только эозином, но й добавкой канцерогена. Присутствие же оксибензола вовсе не отражается на кинетике его окислительного превращения.

Влияние добавки фенолов раз. ного строения на кинетику фотодеградации 3,4-бензпирена принципиально противоположно: оксибензол ускоряет этот процесс, а 5-метилрезорцин его замедляет. Эта закономерность сохраняется и при

значительном повышении концентрации реагентов (см. данные для четвертой группы в табл. 1). Торможение процесса вызывает и эозин, который наряду с этим сенсибилизирует окисление обоих фенолов примерно в одинаковой степени. 3,4-Бензпирен при фотоокислении 5-метилрезорцина вполне отчетливо является сенсибилизатором, а при соокислении с оксибензолом - ингибитором.

Организация окисления в составе бинарной смеси отражается не только на кинетике, но и на механизме деградации каждого из реагентов. Нам представляется, что косвенно такое воздействие может быть охарактеризовано изменением интенсивности окраски раствора. Окислительные превращения 3,4-бензпирена и каждого из фенолов в отдельности связаны с появлением в смеси окрашенных продуктов (хиноны и другие диоксипроизводные, вторичные уплотненные продукты). Однако растворитель этанол сам по себе в таких условиях окрашенных продуктов не образует. На рис. 2 изображена кинетика формирования окрашенных продуктов при соокислении канцерогена и 5-метилрезорцина, т. е. изменения оптической плотности раствора при поглощении в области 490 нм, выраженной в процентах от показателя для чистой воды. Кривая 1 относится к экспериментально-наблюденным изменениям при раздельном фотоокислении 3,4-бензпирена. Кривая 2 построена исходя из предположения об аддитивности эффекта, т. е. по данным для раздельных превращений каждого из компонентов, а кривая 3 отражает фактическую картину при соокислении смесн. Оказывается, формирование окрашенных компопентов в реакционной смеси для бинарной системы сущест- 
венно интенсифицировано по сравнению с ожидаемым. Основанный на этом вывод об изменении механизма превращений находит подтверждение и в итоге хроматографического разделения реакционных смесей в тонком слое активной окиси алюминия. В результате этой операции выявляется существенное различие в качественном составе продуктов лревращения 3,4-бензпирена - раздельного или совместного с фенолами - при одинаковой степени его деградации. Раздельное фотоокисление канцерогена приводит к преимущественному образованию оксипроизводных, выход которых снижается лри его соокислении с фенолом и, особенно, с 5-метилрезорцином.

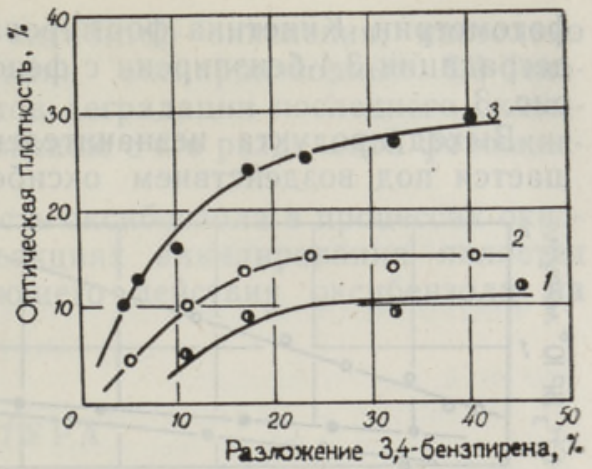

Рис. 2. Кинетика образования окрашенных продуктов деградации 3,4-бензпирена.

1 - раздельное фотоокисление 3,4-бензпи рена, 2 - расчетно-теоретическая кривая для соокисления 3,4-бензпирена с 5-метилрезорцином, 3 - экспериментальные данные для бинарной смеси.

Таблица ?

Кинетика образования 5-метил-3,4-бензпирена

\begin{tabular}{|c|c|c|c|}
\hline \multirow[b]{2}{*}{$10^{19}$ Дозант/мл } & \multirow[b]{2}{*}{$\begin{array}{l}\text { Снижение исход- } \\
\text { ной концентрации } \\
3,4 \text {-бензпирена, \% }\end{array}$} & \multicolumn{2}{|c|}{ Выход 5-метил-3,4-бензпирена } \\
\hline & & $\begin{array}{l}\text { абсолютный, } \\
10^{-8} \text { мольімл }\end{array}$ & $\begin{array}{c}\text { относительный от } \\
\text { разложенного } \\
\text { 3,4-бензпирена, \% }\end{array}$ \\
\hline
\end{tabular}

3,4-Бензпирен, $2 \cdot 10^{-4} \mathrm{M}$

$\begin{array}{rrrr}11,6 & 11 & 0 & 0 \\ 16,3 & 19 & \sim 0,2 & \sim 5,0 \\ 21,0 & 31 & 0,27 & 4,5 \\ 30,4 & 45 & 0,41 & 4,8\end{array}$

3,4-Бензпирен, $2 \cdot 10^{-4} \mathrm{M}+$ оксибензол, $6 \cdot 10^{-4} \mathrm{M}$

$\begin{array}{rrrr}6,9 & 10 & 0,28 & 14,7 \\ 11,6 & 18 & 0,35 & 10,7 \\ 16,3 & 27 & 0,39 & 7,5 \\ 21,0 & 42 & 0,48 & 6,0 \\ 25,7 & 50 & 0,46 & 5,0\end{array}$

3,4-Бензпирен, $2 \cdot 10^{-4} \mathrm{M}+5$-метилрезорцин, $5 \cdot 10^{-4} \mathrm{M}$

$\begin{array}{rrrr}6,9 & 3 & 0,44 & 73 \\ 9,0 & 6 & 0,47 & 59 \\ 11,6 & 10 & 0,75 & 31 \\ 16,3 & 16 & 0,85 & 22 \\ 21,0 & 23 & 1,07 & 24 \\ 25,7 & 32 & 1,22 & 20 \\ 30,4 & 40 & 1,44 & 20\end{array}$

Наиболее доказательным, однако, следует считать изменение выхода 5-метилпроизводного 3,4-бензпирена, связанное с воздействием фенолов. Формирование этого продукта в процессе фотодеградации 3,4-бензпирена качественно установлено в работе [26], где в качестве растворителя использован метанол. В данном эксперименте 5-метил-3,4-бензпирен не только идентифицирован в реакционной смеси, но выход его определен с достаточной достоверносгью при помощи количественной УФ-спектро- 
фотометрии. Кинетика формирования его при раздельной и совместной деградации 3,4-бензпирена с фенолами охарактеризована в табл. 2 и на рис. 3.

Выход продукта незначителен в первом случае, несколько повышается под воздействием оксибензола и значительно возрастает при

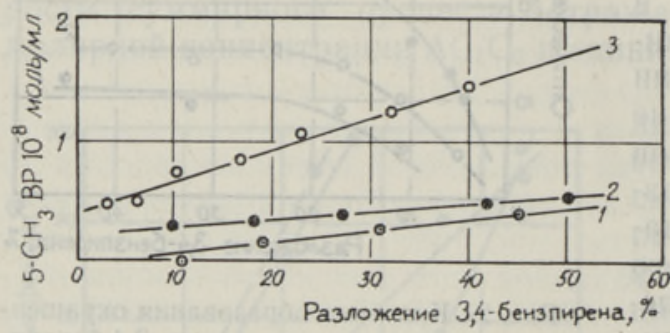

Рис. 3. Кинетика образования 5-метил-3,4-бензпирена.

1 - раздельное фотоокисление 3,4-бензпирена, 2 соокисление 3,4-бензпирена с оксибензолом, 3 - соокисление 3,4-бензпирена с 5-метнлрезорцином. соокислении с 5-метилрезорцином, который, как известно, служит источником метильных радикалов при активированном разложении. В первых двух случаях метильные радикалы являются продуктом фоторазложения этанола, причем атака ими молекулы 3,4-бензпирена происходит у наиболеє реакционноспособного угле. родного атома в положении 5 и ее облегчает наличие оксибензола.

Во втором столбце табл. 2 показана доля 5-метилпроизводного в сумме продуктов превращения 3,4-бензпирена (последняя приравнена количественно к убыли канцерогена в процессе), которая достигает $73 \%$ на начальном участке. В дальнейшем же скорость образования оксипроизводных, очевидно, существенно возрастает и относительный выход метилпроизводного снижается до $20 \%$ от суммы продуктов.

В составе реакционной смеси обнаружен также продукт, структуру которого с помощью одних лишь спектров поглощения с полной достоверностью установить не удалось; судя по ним (максимумы поглощения в области $286,298,355,370,390$ и 404 нм) он представляет собой диме-

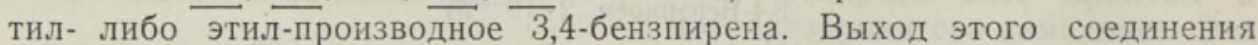
весьма незначителен при раздельной деградации канцерогена и увеличение его примерно одинаково стимулируется присутствием любого из. испытанных фенолов.

\section{Выводы}

Совместное фотоокисление двух компонентов из трех испытанных в: настоящей работе (3,4-бензпирена, оксибензола и 5-метилрезорцина) при использовании в качестве растворителя $96 \%$-ного этанола как по кинетике, так и по механизму существенно отличается от окислительной деградации каждого из этих реагентов в отдельности.

Соокисление 3,4-бензпирена с фенолами разного строения приводит к диаметрально противоположным результатам: оксибензол ускоряет, а 5-метилрезорцин замедляет деградацию канцерогенного углеводорода. 3,4-Бензпирен, в свою очередь, играет роль ингибитора окисления окснбензола и роль сенсибилизатора при превращениях 5-метилрезорцина (что, естественно, снижает скорость деградации канцерогена).

Оба фенола, очевидно, в сходной мере облегчают реакцию замещения водорода алкильными радикалами у наиболее реакционноспособных атомов углерода в молекуле канцерогена. При этом образование монометилпроизводного 3,4-бензпирена резко усиливается добавкой 5-метилрезорцина - источника метильных радикалов - наряду с менее активным в этом отношенин растворителем - этанолом. С другой стороны, 
этот фенол, известный как сильный ингибитор окисления, настолько активно подавляет реакции образования оксипроизводных 3,4-бензпирена, что суммарный выход продуктов деградации последнего оказывается существенно сниженным по сравнению с его раздельной фотоокислительной деградацией.

Пониженная реакционная способность оксибензола в процессах окисления и его активирующая роль в реакциях алкилирования является наиболее вероятной причиной ускоряющего действия оксибензола на деградацию 3,4-бензпирена.

\section{ЛИ ТЕ Р А Т Р А}

1. Г у бер гр и М., Ки р со У., Изв. АН ЭССР, Хим. Геол., 18, 61 (1969).

2. Boutwell R. K., Phenolic Compounds Metab. Regul. (Chapt. 5). Ed. Finkle, A. Runcles., California. Montreal, 1967.

3. Э м а н у эль Н. М., В сб́: Фенольные соединения и их биологические функции. М., 1968, c. 311 .

4. Murakami H., Yamafiy i K., Kyushu Daigaku Nokakibu Kakugei Zasshi, 24, 19 (1969), (C. A. 71, 29139d).

5. Matsuura T., Yoshimura N. и др., Tetrahedron Lett., No. 21, 1669 (1969).

6. Matsuura T., Nishin g a A. и др., Tetrahedron Lett., No. 21, 1673 (1969).

7. Bertetti F. A. A., Diss. Abstr., B28, No. 10, 3989 (1968).

8. Joschek H. I., Miller S. T., J. Am. Chem. Soc., 88, 3273 (1966).

9. Jos che k H. I., Miller S. T., J. Am. Chem. Soc., 88, 3269 (1966).

10. Matsuura T., O mura K., Nakashima R., Bull. Chem. Soc. Japan, 38, 1358 (1965)

11. O mur a K., M a t s u u r a T., Tetrahedron, 24, 3475 (1968).

12. G üsten H., Kir s ch G., S chult e-Froh lin de D., Tetrahedron, 24, 4393 (1968).

13. G ibs on D. T., Science, 161, 1093 (1968).

14. Д ур мидзе С. В., у грехлидзе Д. Ш., Дзикия А. Н., Докл. АН СССР, 184, 466 (1969).

15. 3 а п р о е то в М. И., В сб.: Фенольные соединения и их биологические функции. M., 1968 , c. 109.

16. Ribbons D. W., Cha pman P. J., Biochem. J., 106, 44P (1968).

17. Jussot-Dubien J., Lescleux R., Triplet State, Proc. Int. Symp., Beirut. Lebanon, 1967, p. 197.

18. Cusa chs L. C., Steele R. H., Int. J. Quantum Chem. Symp., No. 1, N. Y., 1967, p. 175 .

19. Kuratsune M., H ir oh a t a T., Nat. Cancer Inst. Monogr., No. 9, 117 (1965).

20. D i ner S., Electronic Aspects of Biochemistry, N. Y., 1964, p. 237.

21. R o n di a D., Ind. Chim. Belge, 32 (Spec. No.), No. 1, 495 (1967).

22. Ro ndia D., D e l w a id e P., Biochem, Pharmacol., 17, 2171 (1968)

23. Di p ple A., L a w le y P. D., B r o okes P.. Eur. J. Cancer, 4, 493 (1968).

24. H a r r is A. Z., Diss. Abstr., B28, No. 10, 4088 (1968).

25. П а альме Л., Г у бер гр иц М., Изв. АН ЭССР, Хим. Геол., 17, 99 (1968).

26. П а льм е Л., Г у бе р г иц М., Изв. АН ЭССР, Хим. Геол., 20 (в печати).

27. Kunte H., Z. Krebsforsch., 72, 57 (1969).

28. П а а льме Л., Г у бе рг риц М.. Изв. АН ЭССР, Хим. Геол., 17, 425 (1968).

29. К и р со У. Э., К уй в К. А., Г у б е р г иц М. Я., Ж. прикл. хим., 40, 1583 (1967).

30. К и р со У. Э., Г у б е рг риц М. Я., К у йв К. А, Ж. прикл. хим., 41, 1257 (1968).
Институт химии
Академии наук Эстонской ССР
Поступила в редакцию $9 / \mathrm{X} 1970$

\section{UUVE KIRSO, M. GUBERGRITS}

\section{3,4-BENSOPUREENI, FENOOLI JA 5-METUOLRESORTSIINI KOOSOKSODEERIMISE KINEETIKA ULTRAVIOLETTKIIRGUSEGA AKTIVEERIMISEL}

Uuriti 3,4-hensopüreeni, fenooli ja 5-metüülresortsiini koosoksüdeerimis! 96\%-lises etanoolis, kasutades aktiveerimiseks ultraviolettkiirgust ulatuslikus lainepikkuste piirkonnas. Leiti, et uuritavad ühendid avaldavad mōju üksteise lagunemiskiirusele, kusjuures muutub 
ka lagunemisprotsessi mehhanism. Oksübenseeni olemasolu süsteemis kiirendab, 5-metüülresortsiini olemasolu aga aeglustab kantserogeense süsivesiniku lagunemist. Mõlemad uuritud fenoolid kiirendavad 3,4-bensopüreeni metüleerimist. 5-metüülresortsiin esineb seejuures üheaegselt nii metüülgruppide allikana kui ka 3,4-bensopüreeni oksüdeerimise pidurdajana.

UUVE KIRSO, M. GUBERGRITS

\section{PHOTO-INDUCED COOXIDATION KINETICS OF 3,4-BENZOPYRENE, PHENOL AND 5-METHYLRESORCINOL}

Cooxidation of 3,4-benzopyrene, phenol and 5-methylresorcinol induced by ultraviolet light irradiation in 96 per cent ethanol medium has been studied. The investigation of the reaction rate constants shows that the all compounds exert an influence on the rate of vxidation. Phenol accelerates and 5-methylresorcinol decelerates the photo-oxidation of cancerogenic hydrocarbon. Both phenols studied accelerate the methylation of 3,4-benzopyrene in 5-position. 